\title{
La Medicina Legal y el delito de violación en Chile (1875-1922)
}

\author{
Alejandra Palafox Menegazzi (*) \\ $\left({ }^{*}\right) \quad$ orcid.org/0000-0003-1936-5432. CONICYT, Instituto de Estudios Sociales y Humanísticos. \\ Universidad Autónoma de Chile. alejandra.palafox@uautonoma.cl
}

Dynamis

[0211-9536] 2020; 40(1): 125-146

http://dx.doi.org/10.30827/dynamis.v40i1.15703
Fecha de recepción: 16 de abril de 2019

Fecha de aceptación: 4 de noviembre de 2019

SUMARIO: 1.-Introducción. 2.-La interpretación conservadora en los primeros comentaristas del Código. 3.-Viraje interpretativo: sistematización e institucionalización de la Medicina Legal en la academia chilena. 3.1-El ámbito médico. 3.2-El ámbito jurídico. 4.—La pericia. 4.1—La centralidad del himen. 4.2-Violencia y práctica forense. 5.-Conclusiones.

RESUMEN: En el presente artículo estudiamos el viraje interpretativo impulsado por los principales exponentes de la Medicina Legal en Chile, ante la resolución conservadora de las controversias teóricas suscitadas por el llamado «principio de ejecución», relativo al delito de violación, desde su aparición en la primera sistematización penal y hasta las primeras dos décadas del siglo xx. Mediante un análisis de documentos normativos, obras bibliográficas y colecciones de revistas médico-jurídicas especializadas, constatamos cómo el proceso de significación de este «principio», lejos de quedar establecido en 1875 , fue elaborado y modificado paulatinamente, gracias sobre todo a la labor desempeñada desde los principales impulsores de la Medicina Legal en el país. Asimismo, con el objetivo de conocer cuál fue la actuación del peritaje médico legal en la comprobación de los delitos de violación y de observar la implementación que el contenido teórico tuvo en la práctica, analizamos cien procesos judiciales por violación, incoados en los tribunales criminales de Santiago y Valparaíso entre 1890 y 1920. Interpretando los discursos médicos y penales considerados como creadores de una realidad concreta, ahondamos en los procesos de alianza e institucionalización médicojurídica dentro de esta rama del conocimiento y consideramos su implementación material en las labores periciales encargadas por los tribunales criminales, para mostrar, así, cómo estas acciones coadyuvaron a reformular, reconstruir y consolidar una longeva desigualdad penal.

PALABRAS CLAVE: medicina Legal, principio de ejecución, violencia sexual, Chile, siglos XIX y XX.

KEYWORDS: legal medicine, execution principle, sexual violence, Chile, XIX and XX centuries. 


\section{Introducción $\left(^{*}\right)$}

La complejidad normativa y el vacío legal que acompañaron la regulación penal de las agresiones sexuales en Chile durante las primeras décadas de independencia política del país comenzaron a suplirse con la publicación en 1875 del primer Código Penal de la República ${ }^{1}$. Dentro de esta sistematización, y teniendo como inspiración principal los códigos penales español (1848) y belga (1867), las distintas tipificaciones de delitos sexuales fueron comprendidas dentro de la categoría de "Crímenes y simples delitos contra el orden de las familias y contra la moralidad pública ${ }^{2}$ y no ya en la de «Delitos contra las personas» ${ }^{3}$, por interpretar, siguiendo la tendencia imperante en los cuerpos legales europeos y americanos, que no era este el bien jurídico contra el que atentaban ${ }^{4}$.

(*) Investigación financiada por el Proyecto: CONICYT-FONDECYT, Posdoctorado número 3180184.

1. Entre 1810 y 1874 tuvo lugar un periodo intermedio para la legislación penal en Chile en el que las leyes republicanas convivieron con la caótica normativa colonial. Iñesta Pastor, Emilia. El Código Penal Chileno de 1874. Revista Chilena de Historia del Derecho. 2003-2004; 19: 298299. Al igual que lo ocurrido en otros territorios iberoamericanos desde el siglo XVIII, en lo que a la regulación de los ilícitos sexuales se refiere, la caída en desuso de las severas penas recogidas en algunas disposiciones fue suplido en la práctica por un amplio arbitrio judicial. Matus Acuña, Jean Pierre. La doctrina penal de la (fallida) recodificación chilena del siglo XX y xxl. Política Criminal. 2010; 9 (5): 144. Para un análisis de la situación normativa relativa a las agresiones sexuales previa a la codificación, pueden consultarse, entre otros, los trabajos de: Salinas, René. Violencias sexuales e interpersonales en Chile tradicional. Historia Social y de las Mentalidades. 2000; 4: 13-49 y Rojas Gómez, Mauricio F. Las voces de la justicia. Delito y sociedad en Concepción (1820-1875). Atentados sexuales, pendencias, bigamia, amancebamiento e injurias. Santiago: CIDBA; 2008. Ambos autores ahondan en los valores normativos que, presentes dentro y fuera del ámbito legal, reglaron el funcionamiento de la justicia ante las agresiones sexuales. Para análisis centrados específicamente en el ámbito de la comprobación delictiva, pueden consultarse: González, Yéssica. «Consiguió su instinto dejándome enferma...». Alcances y prácticas de justicia frente al delito de violación en Concepción en el siglo XIX. Revista Austral de Ciencias Sociales. 2018; 32: 41-58 y Celis Valderrama, Nicolás. «Ahora veremos lo que tiene esta niñita». El cuerpo como prueba de las violencias sexuales en el Valle Central de Chile, 1780-1830. Historia y Justicia. 2018; 11: 206. Hasta la promulgación del Código de Procedimiento Penal de 1906 fue común que los magistrados también fundamentaran sus sentencias en las leyes de Partidas y, en especial, en la P. 7.26.1, relativa a la puesta en libertad de los acusados criminalmente ante la falta de pruebas.

2. Así quedó estipulado en el título séptimo de dicho código, con clara influencia del homónimo título séptimo del código belga: «Des crimes et des délits contre l'ordre des familles et contre la moralité publique».

3. Dentro de esta categoría figuraron los delitos de homicidio, infanticidio, lesiones corporales, duelo, calumnia, e injurias.

4. Nos referimos a los «cuerpos legales americanos» en los que los delitos sexuales no eran considerados delitos «contra las personas», sino contra otros bienes jurídicos, tales como el 
Fue dentro de esta categoría donde se insertaron los artículos 361 y 362, relativos al delito de «violación», crimen definido, por la comisión encargada con base al proyecto presentado por Manuel Rengifo ${ }^{5}$, mediante la plasmación de lo contenido en el código 363 de la legislación española ${ }^{6}$. A pesar de la conformidad de la comisión por concebir formalmente este delito como un acto dirigido contra el orden de las familias y la moralidad pública, la falta de solidez de este principio quedó evidenciada de manera temprana, como consta ya en las impresiones publicadas en 1886 por el jurista, comentarista y promotor fiscal del ramo criminal de Santiago, Robustiano Vera ${ }^{7}$, quien no dudó en reivindicar que en la violación, a diferencia de otros delitos de la misma categoría como el adulterio, el estupro o el rapto, se divisaba «un ataque directo contra la persona» ${ }^{8}$.

En atención a lo estipulado en el artículo 361, se incurría en un delito de violación «yaciendo» con una mujer bajo tres circunstancias concretas: haciendo uso de fuerza o intimidación; cuando la mujer se hallase privada de sentido o razón o cuando esta fuese menor de doce años cumplidos ${ }^{9}$. Asimismo, en el artículo 362, extraído a su vez del artículo 374 del código belga, quedó establecido que los delitos de los que trataba el párrafo anterior se considerarían consumados desde que hubiese «principio de ejecución» ${ }^{10}$.

orden de las familias, la honestidad o la moralidad pública. Podemos considerar al respecto: los códigos penales de Brasil (1830 y 1890), el Código Penal de Perú (1863), el Código Penal del Distrito Federal y Baja California (1871), el Código Penal de los Estados Unidos de Colombia (1873) o el Código Penal de Argentina (1886), entre otros. Conscientes de las controversias jurídicas que ha suscitado la definición del concepto de «bien jurídico» en la historia penal, y en atención a la doctrina nacional, entendemos como bienes jurídicos ciertos intereses y valores que el derecho se ocupa de proteger. Garrido Montt, Mario. Derecho Penal. vol. 2. Santiago: Editorial Jurídica de Chile; 2007, p. 15.

5. Fernández, Pedro Javier. Código Penal de la República de Chile. Explicado y anotado por Pedro Javier Fernández. vol. 2, Santiago de Chile: Imprenta, Litografía y Encuadernación Barcelona; 1899, p. 100.

6. Artículo 363 del Código Penal de España de 1848.

7. De Ramón, Armando; Acevedo Fagalde, Ema y Valdivieso, Patricio. Biografías de Chilenos: miembros Poderes Ejecutivo Legislativo y Judicial (1876-1973). vol. 4. Santiago: Universidad Católica de Chile; 2003, p. 247.

8. Vera, Robustiano. Código Penal de la República de Chile. Santiago, Imprenta de la Librería Americana de Carlos, 1886, p. 296. La primera edición de esta obra fue publicada en 1883.

9. Artículo 361 del Código Penal de Chile de 1874.

10. «Los delitos de que trata este párrafo se consideran consumados desde que hay principio de ejecución». Artículo 362 del Código Penal de Chile de 1874. En el artículo 374 del código belga, relativo a los delitos de violación atentados al pudor, se contemplaba: «L'attentat existe dèsqu'il y a commencement d'exécution». 
Desde su promulgación, ambos artículos suscitaron controversias exegéticas, dentro del ámbito penal y médico legal. Si bien quedaba claro que el delito de violación era un ilícito que podían cometer sólo los varones y sólo sobre víctimas femeninas, al no especificar en qué consistía exactamente el acto de «yacer», el referido "principio de ejecución» admitía múltiples interpretaciones.

En este artículo, buscamos demostrar cómo fueron algunos de los principales representantes nacionales de la Medicina Legal, ciencia auxiliar en formación, concebida para «la aplicación de los conocimientos médicos al funcionamiento de la justicia» ${ }^{11}$, dada la centralidad del peritaje forense en la comprobación delictiva de este tipo de ilícitos, quienes se encargaron de suplir el vacío legal presentado,virando radicalmente el rumbo de las interpretaciones que habían imperado hasta el momento.

Para ello, decidimos ahondar en el estudio del tratamiento médico legal y jurídico del «principio de ejecución» contenido en el Código Penal, considerando que su proceso de significación fue elaborado y modificado paulatinamente entre los años 1875 y 1922, gracias sobre todo a la labor desempeñada desde los principales impulsores de la Medicina Legal en el país. Constatamos nuestra hipótesis mediante la revisión de diversas obras bibliográficas y colecciones de revistas especializadas, entre las que destacamos Revista Médica de Chile, Revista Forense Chilena y Anales de la Universidad de Chile, tres de los principales órganos de difusión médica, penal y académica durante el marco temporal considerado ${ }^{12}$.

Mediante el análisis de estas fuentes, buscamos también conocer algunos de los criterios que imperaron en la comprobación médico-legal del delito de violación, a nivel teórico, ahondando en el tratamiento de los cuerpos de las víctimas en cuanto «cuerpos del delito» ${ }^{13} \mathrm{y}$ «escenas del crimen» ${ }^{14}$, dada

11. Puga Borne, Federico. Compendio de Medicina Legal adaptado a la legislación chilena. Santiago: Imprenta Cervantes; 1900, p. 5

12. Buscamos constatar nuestra hipótesis con la revisión de obras bibliográficas y tres de los principales órganos de difusión médica, penal y académica, disponibles en los fondos documentales de la Biblioteca Nacional. Si bien la edición de las tres revistas seleccionadas se emplazó en la capital, su vocación no fue localista y recogieron los trabajos de intelectuales y profesionales chilenos y extranjeros.

13. Araya, Alejandra. Violación, aborto y embriones: las fronteras del estado laico y de una sociedad de derechos en perspectiva histórica. En: Coloquio. Violación y aborto: historia, justicia y Derechos en Chile. Santiago: Universidad de Chile; 2015, p. 12.

14. Quinlan, Andrea. The techno scientific witness of rape: contentious histories of law, feminism, and forensic science. Toronto: University of Toronto Press; 2007, p. 16. 
la idiosincrasia del delito contemplado. Atendemos también a los posibles daños morales contemplados, considerando que, al encontrarnos en una época pre-psiquiátrica, los daños psíquicos aludidos estuvieron articulados en discursos alternativos sobre el honor ${ }^{15}$. Asimismo, analizamos cien procesos judiciales por violación, incoados en los juzgados del crimen de Santiago y Valparaíso entre 1890 y 1920, con objeto de comprobar de qué manera los criterios teóricos observados se implementaron en el foro.

Nuestro marco temporal engloba los procesos de formación y consolidación de la modernización penal chilena, materializada con la promulgación del Código Penal de 1875 y del Código de Procedimiento Penal de 1906 y supone un periodo clave para la Medicina Legal del país, pues, pese a sus décadas de historia, fue a partir de estos años cuando se constituyó como una «disciplina más autónoma y con ambición rectora» ${ }^{16}$. El cierre de nuestra cronología en 1922 se justifica con la publicación de la obra «Apuntes de Derecho Penal» del profesor de Medicina Legal Raimundo del Río, autor determinante en el establecimiento de la interpretación que sobre el «principio de ejecución» imperó en la jurisprudencia chilena hasta la reforma penal de $1999^{17}$.

A lo largo del siglo xix la Medicina Legal en Occidente pasó paulatinamente a constituir un cuerpo de conocimiento y experiencia reconocido por las autoridades judiciales ${ }^{18}$. Este proceso, lejos de ser homogéneo, presentó ritmos, conflictos y matices diversos en cada contexto. Como analiza Georges Vigarello, desde finales del siglo XVIII y a lo largo del siglo xIX para el contexto francés ${ }^{19}$, el incremento de su autoridad y competencias dentro del funcionamiento de la justicia penal, dotó a esta materia de un carácter «científico», estableciendo nuevos parámetros en la comprobación del

15. Pese a no haber encontrado paralelismos en la obra de los autores aquí analizados, un análisis novedoso sobre el concepto de trauma en el tratamiento forense del delito de violación en un periodo pre-psiquiátrico es el desarrollado por: Ruberg, Willemijn. Trauma, body, and mind: forensic medicine in nineteenth-century Dutch rape cases. Journal of the History of Sexuality. 2013; 22: 85-104.

16. Correa Gómez, María José. «No siempre (las) tripas Ilevan pies». Toxicología, análisis científico y condiciones procesales en la justicia chilena, 1877-1907. Revista Historia y Justicia. 2017; 8: 73.

17. Ley 19617, 12 de julio de 1999, Modifica el Código Penal, el código de Procedimiento Penal y otros cuerpos legales en materias relativas al delito de violación.

18. Watson, Katherine. Forensic medicine in Western society: a history. Londres: Routledge; 2001, p. 76.

19. Vigarello, Georges. Historia de la violación (siglos XVI-XX). Madrid: Cátedra; 1999, p. 220-221. 
delito de violación ${ }^{20}$. La evolución de este proceso estuvo caracterizada por el desarrollo de una mayor precisión anatómica, así como por una mayor atención al estado del himen de las víctimas.

Así, los teóricos de esta disciplina, se esforzaron por detallar cuáles debían ser las señales físicas reconocibles que una violación causaba, con objeto de evitar falsas acusaciones, dentro de un criterio moral que hacía sospechar siempre de las mujeres y que deslegitimaba los relatos de aquellas cuyos órganos evidenciaran un comportamiento sexual no acorde con el ideal de castidad y recato imperantes ${ }^{21}$. La obra de Vigarello resulta esclarecedora a la hora de analizar los textos chilenos del periodo contemplado en este estudio, dada la buena acogida que las obras francesas, y en especial la de Ambroise Tardieu, tuvieron entre la comunidad médica chilena e internacional en lo que al tratamiento forense de los delitos sexuales se refiere ${ }^{22}$.

El desarrollo de la Medicina Legal estuvo, por tanto, ligado a las dinámicas científicas y a la influencia que la ley y el derecho tuvieron sobre esas dinámicas pero, como afirma Julia Rudolph, su desarrollo debe ser investigado, también, mediante las formas en que las normas de género moldearon las verdades legales y científicas producidas ${ }^{23}$. Adoptamos aquí el concepto de género como una categoría de análisis histórico ${ }^{24}$, siguiendo el trabajo ya clásico de Joan W. Scott, y retomamos el concepto de «acto performativo», desarrollado por Judith Butler ${ }^{25}$. De esta manera, concebimos las acciones desarrolladas en el ámbito teórico y práctico-forense chilenos como acciones constitutivas de determinadas relaciones de poder, y no ya como constataciones de una realidad dada, advirtiendo cómo la normativa penal y médico-legal analizada contribuyeron a consolidar un determinado y desigual

20. Este proceso no se produjo hasta finales de la centuria en el ámbito anglosajón, casi un siglo más tarde, en comparación con el europeo continental. Watson, n. 18, p. 109. Aquí, su relación con el poder judicial no estuvo exenta de conflictos y la confianza institucional ante su supuesta experticia en la comprobación delictiva fue ampliamente cuestionada. Robertson, Stephen. Signs, marks, and private parts: doctors, legal discourses, and evidence of rape in the United States, 1823-1930. Journal of the History of Sexuality.1998: 8: 353.

21. Vigarello, n. 19, p. 220-225.

22. Watson, n. 18, p. 188.

23. Rudolph, Julia. Gender and the development of forensic science: acase study. The English Historical Review. 2008; 123 (503): 928.

24. Scott, Joan W. El género: una categoría útil para el análisis histórico. In: Amelang, James S. y Nash, Mary, eds. Historia y Género: las mujeres en la Europa Moderna y Contemporánea. Valencia: Universidad de Valencia; 1990, p. 14.

25. Butler, Judith. El género en disputa. Barcelona: Paidós; 2001, p. 47-48. 
orden sexual, acorde con las preferencias ideológicas de sus promotores y elaborado desde la autoridad que la ciencia les confería.

Al respecto, gracias al análisis de las fuentes consultadas, pudimos advertir cómo, a pesar de que lo recogido en la codificación penal republicana, en el tratamiento forense del delito de violación, sobrevivieron y se reprodujeron ideologías de género presentes ya en época colonial, lo que se tradujo en un tratamiento institucional de las víctimas diferenciado. De esta manera, y en atención a los trabajos de Alejandra Araya, observamos cómo para nuestro marco temporal pervivió un concepto de pureza y honor femenino asociados a la castidad y al recato como virtudes, deslegitimando los testimonios de aquellas mujeres que no cumplieran con el ideal deontológico contemplado ${ }^{26}$.Al tiempo, el mantenimiento de una desconfianza institucional generalizada frente a los relatos femeninos impulsó el desarrollo de mecanismos de comprobación delictiva que, acordes con la dinámica imperante en el contexto occidental, estuvieron orientados a evitar posibles falsas acusaciones más que a proteger a las víctimas ${ }^{27}$.

\section{La interpretación conservadora en los primeros comentaristas del Código}

La regulación del delito de violación, dentro de los artículos 361 y 362 de la codificación penal chilena, supuso el surgimiento y mantenimiento, en las décadas siguientes, de importantes controversias exegéticas. En atención a lo expuesto ya por los primeros comentaristas del Código sobre el «principio de ejecución», acto que daría lugar a la comisión de una violación, este debía asimilarse a la tentativa del delito. Al respecto, Pedro Javier Fernández Frías $^{28}$ señalaba en 1877 el carácter excepcional del articulado pues, como

26. Araya, Alejandra. La pureza y la carne: el cuerpo de las mujeres en el imaginario político de la sociedad colonial. Revista de Historia Social y de las Mentalidades. 2004; 8 (1): 81. Estos conceptos, originados en el imaginario cristiano occidental, fueron reformulados dentro del proceso de secularización social que se vivió en el confesional estado chileno. La compleja relación entre valores católicos y el imperativo ético de la ciencia en el ámbito forense chileno han sido analizados en el trabajo de: Fabregat Peredo, Mario. Evolución de la Medicina Legal en Chile: una aproximación a través de las autopsias practicadas por el Doctor Eduardo Lira Errázuriz, entre 1893 y 1905. Asclepio. 2019; 71 (1): 1-12.

27. Quinlan, n. 14, p. 16 y Vigarello, n. 19, p. 225.

28. Diputado del Partido Conservador entre 1882 y 1891, el abogado Fernández Frías fue el jurista encargado de comentar la primera edición de la sistematización penal chilena. De Ramón, n. 7, p. 87-88. 
quedaba recogido para los demás delitos, sólo ameritaban las penas estipuladas los actos consumados, reservándose para los autores de tentativa de crimen o simple delito frustrado una pena inferior en dos grados ${ }^{29}$. Con esta afirmación, el comentarista daba a entender que una tentativa de violación debía de ser castigada con la misma condena que una violación consumada, es decir, con «pena de presidio mayor en su grado máximo a presidio mayor en su grado medio» ${ }^{30}$.

Alejandro Fuenzalida ${ }^{31}$, en sus comentarios al código de 1883, interpretaba, al igual que Fernández, que la tentativa de violación debía de ser castigada como su consumación. Al respecto, recordaba que esta excepción, pese a derivar del código penal belga, se encontraba presente en la jurisprudencia chilena ya desde época colonial, manteniéndose vigente durante la etapa republicana previa a la codificación penal. Durante esta etapa, de hecho, supuestos autores de una violación frustrada habían sido condenados a sufrir una pena capital, a través de sentencias fundamentadas en la ley de Partidas 7.31.2 32 . La explicación ofrecida por el penalista se basaba, por un lado, en la delicadeza del pudor femenino - concebido como una cualidad ligada a su castidad sexual-y, por otro, en la conceptualización del varón como un ser dotado de un apetito sexual irrefrenable e incapaz de reprimirlo una vez iniciados los actos preparativos de la cópula. Así se pronunciaba al respecto:

En efecto, cuando se trata del pudor de la mujer, que se empaña como un purísimo cristal al más leve soplo de la impureza, las consecuencias de la tentativa son casi las mismas que las del crimen consumado: los sufrimientos de la víctima empiezan con el primer acto de ejecución y desde este momento está tan bien perdido el honor material (...). Por otra parte, la tentativa de este crimen es de tal naturaleza que casi no deja abrigar la esperanza de que el

29. Artículos 50 y 52 del Código Penal de Chile de 1874. Fernández, n. 5, p. 100.

30. Esto se traducía en desde entre tres años y un día y cinco años de Presidio hasta entre cinco años y un día y quince años de Penitenciaria. Fernández, n. 5, p. 95. Vera, n. 8, p. 297.

31. Tras licenciarse en 1863, Fuenzalida ejerció como juez letrado de Antofagasta y juez de lo criminal en Lima. Fue Ministro de la Corte de Apelaciones de Iquique en 1884 y un prolijo autor de disertaciones jurídicas. De Ramón, n. 7, p. 121.

32. Fuenzalida, Alejandro. Concordancias y comentarios del Código Penal Chileno. tomo III, Lima: Imprenta Comercial; 1883, p. 35. En el momento de su publicación, Fuenzalida ejercía como juez letrado del ramo criminal en Lima, ciudad que se mantuvo bajo la ocupación chilena entre 1881 y 1883. Matus, Jean Pierre. Fernández, Fuenzalida y Vera: Comentaristas, autodidactas y olvidados. Análisis diacrónico y sincrónico de la doctrina penal chilena del siglo XIX. lus et Praxis. 2006; 12 (1): 34. 
delincuente se arrepienta; puesto que en esos momentos próximos a la delicia carnis (sic) ${ }^{33}$, el hombre, completamente dominado por el apetito, nada teme ni nada ve que no sea la mujer que se lo causa ${ }^{34}$.

Robustiano Vera, por su parte, pese a reconocer también la excepcionalidad del tratamiento del delito de tentativa de violación y cómo esta garantizaba el «honor de toda mujer», - reproduciendo un concepto de honor femenino basado en su castidad - advertía la necesidad de distinguir entre un «acto serio» que estableciera «claramente la intención del culpable» y un «acto preparativo», como podría ser un «abrazo u otra manifestación aislada» que no demostrara «la intención clara y directa de ejecutar estos hechos» ${ }^{35}$.

Ante las imprecisiones recogidas en los artículos analizados, por tanto, los tres comentaristas mantuvieron una actitud conservadora, en relación con la doctrina de origen colonial, coincidiendo en interpretar que la tentativa del delito de violación ameritaba la misma pena que el delito consumado, pero dejando al arbitrio judicial la decisión sobre qué actos debían de ser considerados tales ${ }^{36}$. Sus interpretaciones contemplaron las consecuencias morales que el delito tratado podía ocasionar sobre el honor de las víctimas, ligado a un modelo de mujer de-sexualizado y cimentado sobre la castidad como máxima virtud.

\section{Viraje interpretativo: sistematización e institucionalización de la Medicina Legal en la academia chilena}

\subsection{El ámbito médico}

A pesar de que el proceso de institucionalización de la Medicina Legal en la naciente República de Chile ya había iniciado con la creación en 1833 de la cátedra homónima de la Escuela de Medicina, ubicada en el antiguo Instituto Nacional, fue sólo en 1900, cuando tuvo lugar la primera sistematización

33. Entendemos que refiere a los «delicta carnis», categoría medieval empleada para aludir a los delitos sexuales.

34. Fuenzaliza, n. 32, p. 35.

35. Vera, n. 8, p. 297.

36. Recordamos que, a diferencia de lo estipulado en el Código Penal, la normativa colonial se reconocía formalmente y se aplicaba sólo sobre vírgenes, monjas o viudas honestas, mujeres consideradas honradas con base en su comportamiento y fama sexual. Celis, n. 1, p. 206. 
en el país de la historia, los principios reguladores y las funciones a las que esta ciencia debía atender ${ }^{37}$. Esta sistematización, materializada en la obra de casi novecientas páginas, Compendio de Medicina Legal adaptado a la legislación chilena, corrió a cargo del doctor Federico Puga Borne, profesor titular de la cátedra de Higiene y Medicina Legal de la Universidad de Chile desde 1883. Frente a la existencia de numerosos y detallados manuales de Medicina Legal extranjeros ${ }^{38}$, la obra de Puga Borne respondió a la necesidad de adecuar la enseñanza de esta ciencia a las especificidades de la legislación del país, algo especialmente relevante por lo que al tratamiento de los «atentados contra el pudor y las buenas costumbres» ${ }^{39}$ se refería, dadas las controversias jurídicas suscitadas tras su regulación penal ${ }^{40}$.

$\mathrm{Al}$ respecto, ante las variables acepciones jurídicas admitidas en la práctica forense chilena por los delitos «contra la honestidad», como Puga Borne refería también a los incluidos en el título séptimo del código, este profesor se esforzó por precisar los términos incluidos en la legislación, así como por encauzar la comprobación delictiva dentro de los parámetros científicos ofrecidos por la Medicina Legal ${ }^{41}$. De esta manera, la violación

37. La incorporación en 1833 de la Escuela de Medicina al Instituto Nacional —institución de educación secundaria creada en 1813-, en detrimento de la lastrada Universidad de San Carlos, se mantuvo hasta 1842, año en el que se incorporó a la recién fundada Universidad de Chile. A partir de este año, la Facultad de Medicina, comenzó a encargarse de la formación de la clase médica del país. Serrano, Sol. Universidad y nación. Chile en el siglo xIx. Santiago: Editorial Universitaria, Dibam; 2016, p. 70.

38. Cabe advertir que en lo que al tratamiento médico-legal de los delitos sexuales se refiere, el médico chileno siguió, principalmente, los tratados de Tardieu, Vibert, Taylor, Ramón y Vega, Parent Duchatelet, Beauvais, Hofmann y Devergie, considerando para las psicopatologías asociadas, además, las obras de importantes criminalistas y sexólogos europeos como el italiano Cesare Lombroso o el austro-alemán Richard von Krafft-Ebing. Esta consideración no supuso una mera reproducción de la doctrina extranjera sino una selectiva asimilación de determinados principios bajo el criterio de adecuarlos a las particularidades de la normativa nacional.

39. Tras analizar la disertación posterior, interpretamos que el autor alude con «atentados contra el pudor y las buenas costumbres» a los delitos incluidos por el Código Penal bajo la categoría de «Crímenes y simples delitos contra el orden de las familias y contra la moralidad pública» pues las particularidades que refiere pertenecen a varias tipificaciones delictivas incluidas en este grupo.

40. Puga, n. 11, p. 63.

41. Además de ocupar el cargo de director del Instituto de Higiene en 1892, desde 1873 Puga Borne desarrolló una intensa carrera política, siendo elegido senador, diputado y ministro de Estado en diversas ocasiones. De Ramón, n. 7, pp. 275-276. 


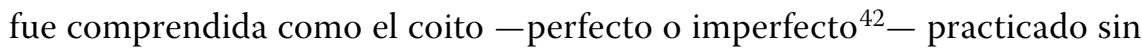
el consentimiento de la mujer ${ }^{43}$.

Por lo que respectaba al ya referido principio de ejecución, a diferencia de lo defendido por los comentaristas analizados y de la tendencia imperante en las cortes chilenas ${ }^{44}$, según Puga Borne, este debía asimilarse a la consumación del coito, entendido como la «penetración»o «intromisión» del órgano sexual de la mujer efectuado por el «miembro viril», y no ya a los «actos iniciales que prepara(ba)n el delito» ${ }^{45}$. Con ello, argumentaba, quedaría delimitada la valoración judicial, evitando que quedase «abandonada a un arbitrio sin límites» ${ }^{46}$, y se protegería a hombres inocentes, cuyos actos, en palabras del autor, buscaban «consultar»y «conquistar» el consentimiento de la mujer, sin pretender «vencerlo ni atropellarlo» ${ }^{47}$. Pese a mantener un criterio de honestidad ligado a la castidad de la mujer como virtud, por tanto, la desconfianza sistemática ante los relatos femeninos orientó la interpretación de este profesor, distanciándose de los razonamientos ofrecidos por los comentaristas.

\subsection{El ámbito jurídico}

La aparición del compendio de Puga Borne fue ampliamente celebrada por juristas, sobre todo por quienes advertían las evidentes carencias formativas denostadas por sus pares en materia médico legal - carencias que contrastaban con las décadas de historia de este ramo del conocimiento en la formación de los facultativos-, su creciente presencia en la constatación del delito durante los juicios y su obligatoriedad, recogida en el Código Penal, de asistir a la justicia como peritos, siempre que fueran requeridos ${ }^{48}$. Ante esta situación, el Compendio de Puga Borne aparecía como un importante

\footnotetext{
42. Por coito perfecto, dentro de una lógica androcéntrica y centrada en la reproducción, imperante dentro de la Medicina Legal, se entendía una penetración reiterada del pene en la vagina que diera lugar a la eyaculación del primero.

43. Puga, n. 11, p. 64.

44. Al respecto Puga Borne citaba ejemplos de resoluciones dadas por la Corte Suprema, la Corte de lquique y la Corte de Concepción entre 1879 y 1886.

45. Puga, n. 11, p. 66.

46. Puga, n. 11, p. 66.

47. Puga, n. 11, p. 66-67.

48. Artículo 494, sección 12 del Código Penal de Chile de 1874.
} 
instrumento pedagógico para suplir de manera autodidacta esta ausencia de conocimientos ${ }^{49}$.

En 1902 las crecientes demandas de incluir la formación médico legal a los planes de estudios de la carrera de Leyes fueron, finalmente, satisfechas con el establecimiento de la Cátedra de Medicina Legal de la Facultad de Leyes y Ciencias Políticas de la Universidad de Chile ${ }^{50}$. El primer responsable de organizar e impartir este ramo, y uno de los primeros en elaborar manuales médico-legales dirigidos a juristas en el país fue el abogado liberal Tomás Ramírez Frías ${ }^{51}$.

En atención al programa elaborado por Ramírez, así como a los apuntes de la asignatura, en esta primera fase de la materia, los referidos indistintamente como «delitos de incontinencia»o «delitos contra la honestidad» -dentro de los cuales se englobaban las categorías delictivas de violación, estupro, incesto, corrupción de menores y abusos deshonestos- quedaron, concebidos por el autor como «Atentados contra las personas», y no ya contra el orden de las familias y la moralidad pública ${ }^{52}$. Esta paradójica situación se debía a que, a pesar de los preceptos legales - ampliamente criticados por Ramírez-, este, al igual que lo establecido ya por Vera en sus comentarios, interpretaba que la violación era un delito que atentaba contra la libertad personal de las víctimas, perjudicando su salud y causando su deshonra social ${ }^{53}$.

Sobre la comprobación médico-legal de este delito, Ramírez aclaraba que si bien la «noción fisiológica del coito» comprendía la introducción del miembro viril en la vagina junto con la eyaculación de semen, en su concepto penal, la emisión de esperma no era requerida, coincidiendo con Puga Borne en la aceptación del «coito imperfecto» como determinante para la

49. Latorre, Enrique. Sección bibliográfica. Publicaciones recibidas. Revista forense Chilena. 1900; 14: 378-381.

50. Ramírez, Tomás. Programa de la asignatura de medicina legal. Anales de la Universidad de Chile. 1906; 118:161.

51. De Ramón, n. 7, p. 9. El Decreto de 10 de enero de 1902 ordenaba a los profesores a formar el programa de sus respectivas asignaturas. Muñoz San Martín, Francisco. Estudios sobre Antropología Jurídica (Medicina legal): obra escrita con arreglo al programa universitario formado para el Curso de Derecho. Santiago: Imprenta y Encuadernación «Chile»; 1911, p. 5. Ramírez buscó dotar a esta asignatura de una «tendencia propia y sustancialmente distinta» de la de su homónima impartida en la Facultad de Medicina. Ramírez Frías, Tomás. Apuntes de medicina legal. Santiago: Imprenta y encuadernación; 1907, p. 9.

52. Ramírez, n. 50, p. 170 y Ramírez Frías, n. 51, p. 198.

53. Ramírez, n. 50, p. 199. 
comisión delictiva ${ }^{54}$. El «principio de ejecución»citado en el artículo 362, para Ramírez era asimilable a un «principio de intromisión», explicitado como «intromisión del pene en la vagina de la víctima»o «la penetración del asta viril en la vagina, en condiciones penadas por la ley», si atendemos a los apuntes publicados por Francisco Muñoz, abogado y antiguo alumno de este profesor ${ }^{55}$.Ante la ausencia de intromisión del pene en la vagina de la víctima, por tanto, si bien se podía dar un delito de tentativa de violación o de abusos deshonestos, según los casos, ambas situaciones resultaban insuficientes para condenar al reo por violación ${ }^{56}$.

Esta interpretación fue retomada y reproducida por Raimundo del Río, sucesor de Ramírez como profesor titular en la cátedra de Medicina Legal desde $1918^{57}$. De esta manera, en atención por lo expuesto por Del Río, los actos preparativos a la cópula, tales como «tomar a la mujer violentamente, arrastrarla a un lugar solitario, echarla al suelo, levantarle los vestidos o rasgarle las ropas interiores», así como los actos que implicaban «tocamiento o roce de los órganos sexuales» sin penetración, no podían ser interpretados como un principio de ejecución y, por tanto, pese a poder formar parte de un delito frustrado, no podían ser penados como violación ${ }^{58}$. La adopción y el desarrollo de este viraje interpretativo, de parte de quien fuera uno de los principales representantes del postivismo penal chileno del siglo $\mathrm{xx}^{59}$, supuso su consolidación, dentro de una exégesis médico legal que imperó hasta la reforma penal de $1999^{60}$, a pesar de algunos fallidos intentos por retomar, en las décadas siguientes, la equiparación entre principio de ejecución y tentativa punible ${ }^{61}$.

\footnotetext{
54. Ramírez Frías, n. 51, p. 198.

55. Ramírez Frías, n. 51, p. 199 y Muñoz, n. 51, p. 216.

56. Ramírez Frías, n. 51, p. 202.

57. Del Río, Raimundo. Apuntes de Derecho Penal. Santiago: El Globo; 1922, p. 274 y 278.

58. Del Río, n. 57, p. 280. Reproducido también en Del Río, Raimundo. Elementos de Derecho Penal. Santiago: Nascimento; 1939, p. 494 y 495 y en Del Río, Raimundo. Manual de Derecho Penal. Santiago: Nascimento; 1947, p. 356 y 357

59. Matus Acuña, Jean Pierre. El Positivismo en el derecho penal chileno. Análisis sincrónico y diacrónico de una doctrina de principios del siglo xx que se mantiene vigente. Revista de Derecho. 2007; 20 (1): 176.

60. Como queda demostrado en: Silva, Hernán. Medicina Legal y Psiquiatría Forense. Santiago: Editorial Jurídica de Chile; 1995, pp. 364-365.

61. Considérese, al respecto, Schweitzer, Miguel. El «principio de ejecución» en los delitos de violación. Revista de ciencias Penales. 1945; 8: 25-28. La excepcionalidad de la posición de Schweitzer parece evidente dentro del área, como muestra la omisión de posibles controversias interpretativas en las obras de quien fue profesor de Medicina Legal desde 1928 y hasta mediados de la década
} 


\section{La pericia}

La sistematización de la Medicina Legal en el ámbito universitario capitalino y su creciente relevancia institucional, unidos a la ausencia de un protocolo de actuación pericial para la comprobación del delito de violación ${ }^{62}$, así como al viraje interpretativo sobre su determinación penal, establecido desde esta ciencia auxiliar, supusieron la necesidad de especificar, para el ámbito chileno, cuáles eran los vestigios materiales apreciables por los médicos durante su labor pericial y qué métodos debían adoptarse al respecto.

En atención a lo recogido en las obras consultadas, y en consonancia con la tradición jurídica chilena y extranjera ${ }^{63}$, la comprobación médico forense de un delito de violación debía desarrollarse, primariamente, mediante una detenida observación corporal, principalmente del área genital, de las supuestas víctimas. Al respecto, y a pesar de que, según lo establecido en el Código Penal, la actividad sexual de una mujer no constituía una variable a tener en cuenta a la hora de valorar la comisión de un delito de violación, su verificación pericial, para Puga Borne, resultaba factible sólo en aquellos casos en los que la víctima fuera virgen - condición equiparada a la conservación intacta de su membrana himen - antes de sufrir la comisión delictiva ${ }^{64}$. En las mujeres ya «desfloradas» el perito, privado de elementos de diagnóstico, debía elaborar su valoración mediante signos accesorios e indirectos, tales como «los traumatismos de los órganos sexuales, de las regiones vecinas y de las regiones distantes; la comunicación de enfermedades venéreas; la presencia de manchas de sangre y sobre todo de esperma en el cuerpo o en las ropas de la víctima», signos que, a diferencia del las improntas que un

de los cincuenta, el juez de Menores Samuel Gajardo. Gajardo, Samuel. Manual de Medicina Legal. Normas para la enseñanza jurídica del ramo en las Universidades Latino-americanas. Santiago: Editorial Nascimento; 1939, p. 315.

62. La regulación de las responsabilidades periciales en la investigación judicial, recogida en los artículos 242-267 del Código de Procedimiento Penal significó la prevalencia formal de mujeres tituladas frente a hombres para la realización de exámenes corporales femeninos, así como la definición de la estructura del informe resultante, articulado en descripción de la persona, relación de las operaciones realizadas y conclusiones derivadas. Los detalles sobre cómo debían desarrollarse los exámenes, sin embargo, no fueron normados. Código de procedimiento penal de la República de Chile. Santiago: Imprenta Cervantes; 1906. Esta ausencia de un formato «que permitiera coordinar las necesidades del tribunal con el lenguaje médico» estuvo presente también en el ejercicio forense de las autopsias. Fabregat, n. 26, p. 6.

63. Puga, n. 11, p. 65-90. Vigarello, n. 19, p. 220-221.

64. Puga, n. 11, p. 83. 
acto sexual reciente dejaba en una mujer virgen, según este facultativo, no siempre eran identificables ${ }^{65}$.

Para Ramírez, la comprobación pericial del delito podía desarrollarse atendiendo al cuerpo tanto de la víctima como del agresor, tratando de encontrar en ambos alguno de los factores aludidos por Puga Borne. Sin embargo, sólo los órganos genitales de las víctimas vírgenes podían sufrir alteraciones anatómicas observables por los expertos. Ante las peculiaridades de cada membrana himen - considerada como principal elemento indicador del estado virginal de una mujer-, por otro lado, su estado no parecía un indicador claro de la comisión delictiva, pudiendo, en algunas mujeres, aparecer intacta después de un coito o rota por circunstancias ajenas a la penetración sexual $^{66}$.

La apariencia de la membrana himen, por tanto, no constituía un indicio seguro de la realización coital pues, dada la diferente elasticidad y los orificios que presentaba en cada mujer ${ }^{67}$, así como las diversas conformaciones que el «miembro viril» podía presentar en cada varón ${ }^{68}$, en atención a lo expuesto en los manuales teóricos, existía la posibilidad de que se hubiese producido una agresión sexual con penetración ${ }^{69}$. Asimismo, ante la constatación de una ruptura de himen, los peritos no debían descartar la posibilidad de que esta se debiera a causas ajenas a la desfloración, como podían ser ciertas enfermedades, como la difteria o la viruela; operaciones quirúrgicas o accidentes físicos ${ }^{70}$.

Ante esta situación, durante las primeras décadas del siglo $\mathrm{xx}$, las controversias a la hora de interpretar el estado del himen como vestigio probatorio de un delito de violación se mantuvieron, tanto en el foro como en los espacios más relevantes de discusión científica del país, como lo atestigua la disertación sobre la importancia médico-legal de los traumatismos genitales indirectos del médico de la ciudad de Chillán, el doctor Jerónimo Alvarado Wall ${ }^{71}$.

65. Puga, n. 11, p. 83

66. Muñoz, n. 51, p. 217; Puga, n. 11, p. 71-80.

67. Muñoz, n. 51, p. 189 y 218

68. Puga, n. 11, p. 75.

69. Muñoz, n. 51, p. 189 y 218; Puga, n. 11, p. 77.

70. Puga, n. 11, p. 78; Muñoz, n. 51, p. 219.

71. Son pocos los datos biográficos disponibles sobre este facultativo, quien tras titularse como médico cirujano en 1909 y antes de establecerse en Chillán como médico de ciudad, tuvo la ocasión de viajar comisionado a Europa para ampliar sus conocimientos. Figueroa, Virgilio. 
Como médico de ciudad, Alvarado era consciente de que, en cualquier momento, podía ser llamado como perito para constatar un delito de violación por lo que, enfocado él también no ya a incrementar los medios de constatación de la comisión delictiva sino a evitar la condena de posibles inocentes en los procesos por agresión sexual, como reconoció explícitamente ${ }^{72}$, mostró su preocupación frente a la idea, extendida entre los médicos legistas, de que el himen sólo podía ser lesionado por un contacto sexual con penetración, negando que pudiera ser desgarrado por causas ajenas a la «desfloración» $\mathrm{o}$ «un traumatismo directamente aplicado sobre las partes genitales ${ }^{73}$. Ante esta situación, Alvarado se esforzó por demostrar cómo el himen también podía ser desgarrado de forma indirecta, ejemplificando lo afirmado a través de dos casos clínicos, mediante los que trataba de demostrar que, si bien ocurría de forma rara, el himen podía desgarrarse de forma indirecta y, cuando esto ocurría, dejaba signos propios, pues, a diferencia de un desgarro por causa directa, estas lesiones no eran «radiadas», es decir, no lograban alcanzar el borde libre del himen.

\subsection{Violencia y práctica forense}

Si bien tanto para Puga Borne como para Ramírez era imprescindible que el facultativo procediese lo antes posible también al examen del supuesto agresor «a fin de comprobar la existencia de vestigios y afirmar de este modo su culpabilidad ${ }^{74}$, los documentos de archivo consultados ${ }^{75}$ evidencian que tan sólo doce de ellos fueron reconocidos corporalmente. Estos extraordinarios exámenes, ordenados en su mayoría para constatar rastros de enfermedades venéreas encontrados en las víctimas, sirvieron también para deslegitimar las declaraciones femeninas, en los casos en los que las lesiones vaginales observadas no fueran lo suficientemente profundas, a juicio del perito.

Alvarado Wall, Jerónimo. En: Diccionario Histórico y Biográfico de Chile. 1800-1925. Santiago: Imprenta y Litografía La Ilustración; AÑO. p. 411. Alvarado Wall, Jerónimo. Traumatismos genitales indirectos y su importancia médico-legal. Revista Médica de Chile. 1921; 49: 253-255.

72. Alvarado, n. 71, p. 253.

73. Alvarado, n. 71, p. 253

74. Muñoz, n. 51, p. 220.

75. Se analizaron un total de cien expedientes judiciales, pertenecientes al Archivo Nacional Histórico de Chile, fondos «Judicial Santiago» y «Judicial Valparaíso», secciones «Criminal», años 18901920. Los exámenes médicos fueron desarrollados en ochenta y ocho casos. 
Considerando que una violación implicaba la intromisión del pene en la vagina de una mujer, el cuerpo de los acusados era examinado con objeto de valorar sus genitales y determinar si, efectivamente, por su posible reducido tamaño, la lesión himeneal constatada había sido efectuada con un pene o con otro objeto, descartando, en este caso, la comisión delictiva. Así, por ejemplo, a pesar de las advertencias que los expertos recogían acerca de la elasticidad de esta membrana, en 1894 el médico Eduardo Donoso, durante el proceso por violación de la niña de siete años Mercedes Bernales, concluía su pericia afirmando que la pequeña desgarradura del himen de la víctima, por sus dimensiones, se debía de haber producido introduciéndole el dedo, lo que imposibilitaba que el procesado fuese condenado por violación ${ }^{76}$. Por el contrario, la constatación en 1898 del reducido tamaño del pene de Manuel Méndez, procesado de 29 años, sirvió al doctor Antonio Valdés para concluir que el desgarro himeneal de la víctima, de diez años de edad, se había podido producir por la introducción violenta del pene del acusado pudiendo, así, romper el himen sin franquear la entrada de la vagina, al tener un diámetro poco desarrollado pero superior al pequeño orificio vaginal ${ }^{77}$.

En los procesos por violación en los que la víctima no fuese virgen, ni menor de doce años, ni se encontrara privada de sentido, para que el delito fuese demostrado debía comprobarse que la acción sexual se había ejercido mediante intimidación o fuerza física. La comprobación de este último aspecto debía efectuarse mediante la constatación de lesiones corporalescontusiones, escoriaciones y erosiones, situadas de modo «particularmente característico» en brazos, muñecas, muslos, rodillas, ingles y contorno de la boca- consideradas por la Medicina Legal como muestras de la resistencia ofrecida por la víctima ${ }^{78}$, así como de traumatismos varios sobre los órganos sexuales, tales como equimosis exteriores, extravasaciones sanguíneas en las paredes vaginales; inflamaciones en los grandes labios o desgarraduras en la horquilla, el perineo o la vagina ${ }^{79}$.

76. Violación de la menor Mercedes Bernales, 1894. Archivo Nacional Histórico de Chile, Fondo Judicial Santiago, Sección Criminal, caja 1128, doc. 41, f. 3r. Hemos actualizado las partes transcritas de los documentos de archivo según las normas ortográficas actuales, sin alterar su sentido o valor semántico.

77. Violación de Elisa Alarcón, 1898. Archivo Nacional Histórico de Chile, Fondo Judicial Valparaíso, Sección Criminal, caja 50027, doc. 41, f. 1v.

78. Puga, n. 11, p. 80 y Muñoz, n. 51, p. 220.

79. Puga, n. 11, p. 79. 
A estas lesiones Puga Borne añadía otras de tipo físico y moral, daños que perturbarían el estado nervioso, anímico y general de la salud de las víctimas, causando desde síncopes, delirios, dolores en el pecho y fatigas, hasta una deformación genital, acompañada de palidez plomiza en el rostro, marchitez de la piel, dificultad de las digestiones y extrema debilidad general cuando la desfloración era seguida de relaciones sexuales reiteradas, principalmente en niñas pequeñas ${ }^{80}$. En la práctica procesal, en relación con los daños morales contemplados, si bien el comportamiento de las víctimas fue examinado por las autoridades judiciales, a través del relato de testigos para constatar su probidad - considerada directamente proporcional al recato demostrado- no hallamos ninguna referencia a su estado anímico o nervioso en los exámenes forenses analizados.

En cuanto al examen físico, durante las primeras dos décadas del siglo $\mathrm{xx}$, la virginidad de las supuestas víctimas siguió siendo un elemento central durante la comprobación pericial, como muestra el hecho de que en los casos por violación de mujeres casadas, viudas o con hijos, el examen médico-legal no fuera ni siquiera ordenado por las autoridades judiciales ${ }^{81}$.

Por otro lado, la ausencia de un protocolo normativo a la hora de desarrollar los exámenes, unida a la carencia formativa en materia médico-legal de las autoridades judiciales, ya descritas, se materializaron, en la práctica, en el desarrollo de heterogéneas y cuestionables metodologías a la hora de llevar a cabo las pericias. De esta manera, encontramos en algunos exámenes referencias al estado de los pechos de la supuesta víctima, interpretado como indicador su virginidad. Como quedó recogido en el informe presentado en 1902 por el doctor Daniel Carvallo, tener pechos «desarrollados» y una aureola oscurecida indicaba una ausencia antigua de la virginidad, identificable en aureolas de «tinte sonrosado» ${ }^{82}$.

La búsqueda de marcas de violencia durante la observación médica, por otro lado, quedó reflejada tan sólo en el 39\% de los informes recogidos, constatándose, a su vez, en dieciséis de ellos. Aquí, de nuevo, las conclusiones variaron en función del criterio particular de cada perito. De esta manera,

\footnotetext{
80. Puga, n. 11, p. 80.

81. Sólo en doce de los cien casos revisados los exámenes no fueron ordenados.

82. Adolfo Fuch. Violación, 1902. Archivo Nacional Histórico de Chile, Fondo Judicial Valparaíso, Sección Criminal, caja 50205, doc. 8, ff. 4r-5v.
} 
Gráfico I. Relación de exámenes médicos y búsqueda de violencia ${ }^{83}$

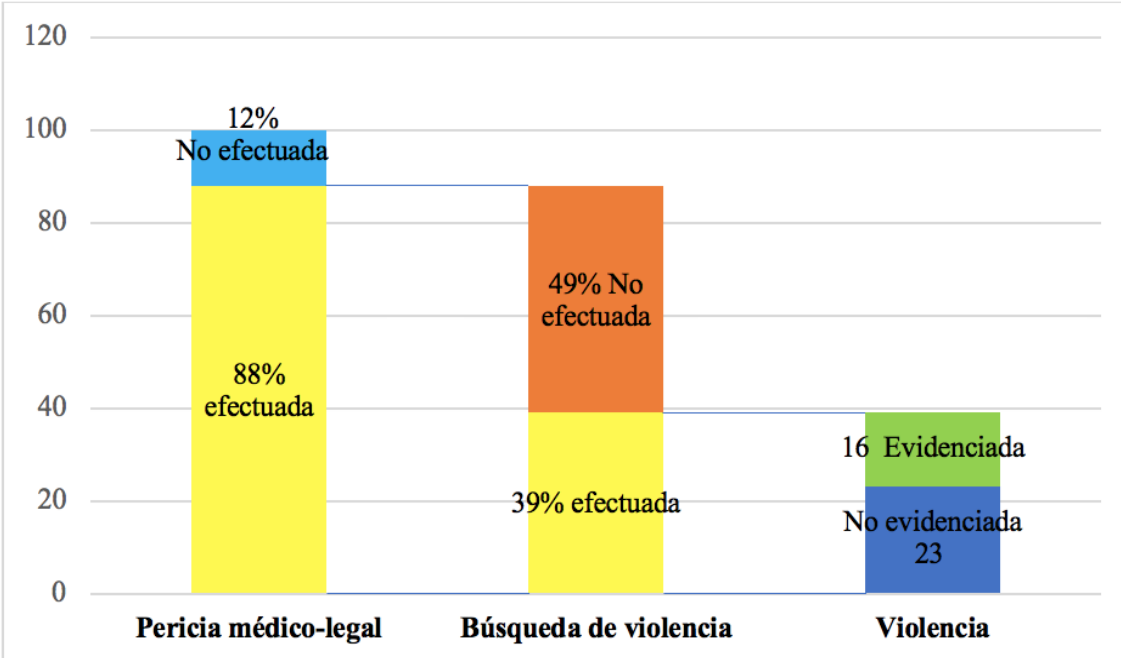

mientras que para algunos, como Eduardo Lira Erráruriz, la presencia de inflamación, equimosis y contusiones en los genitales eran prueba inequívoca de que el acto sexual se había efectuado mediante fuerza física, otros, como Daniel Carvallo, sólo interpretaban como marcas de esta fuerza las marcas o lesiones, supuestamente características, en brazos o muslos ${ }^{84}$, denotando una mayor tolerancia frente a una violencia considerada normal en las relaciones sexuales, así como la extendida idea de que un solo varón debía ejercer una gran fuerza para doblegar la voluntad de una mujer adulta ${ }^{85}$.

Por otro lado, debemos advertir que, a pesar de incluirse en la mayor parte de los procesos analizados, el valor probatorio del examen médico estuvo siempre en entredicho pues, pese poder demostrar que una mujer había sido víctima de una agresión sexual, según las autoridades judiciales,

83. Elaboración propia con base en cien expedientes por violación, pertenecientes al Archivo Nacional Histórico de Chile, fondos «Judicial Santiago» y «Judicial Valparaíso», secciones «Criminal», años 1890-1920.

84. Violación de Udmindia Brito, 1900. Archivo Nacional Histórico de Chile, Fondo Judicial Santiago, Sección Criminal, caja 1234, doc. 15, ff. f. 3r. Violación de Petronila Marchant, 1891. Archivo Nacional Histórico de Chile, Fondo Judicial Valparaíso, Sección Criminal, caja 50027, doc. 25, ff. $1 \mathrm{r}-11 \mathrm{v}$.

85. Vigarello, n. 19, p. 147; Robertson, n. 20, p. 350. 
este no garantizaba la autoría de la misma. Así lo ejemplifica el proceso por violación incoado en Valparaíso en 1898, donde, tras constatar en el cuerpo de la víctima desgarro de himen, inflamación catarral de la vulva y contusión en los órganos genitales externos, la conclusión del perito Enrique Deformes fue que se había procedido «al coito con violencia y repetidas veces» ${ }^{86}$. A pesar de esta verificación pericial, sin embargo, tanto para el promotor fiscal, Luis Yáñez, como para el juez de primera instancia, Carlos Silva Domínguez, los resultados eran sólo presunciones sobre la autoría del delito, por lo que el acusado debía quedar absuelto ${ }^{87}$.

\section{Conclusiones}

La autoridad que Medicina Legal adquirió como ciencia auxiliar del funcionamiento judicial a nivel formal, en lo que comprobación delictiva del delito de violación se refiere, estuvo ampliamente cuestionada en la práctica. A la dificultad teórica de determinar cuándo un delito de violación se había cometido - según los criterios de los principales representantes de la materia en el país - se sumó, por tanto, una actitud de las autoridades reacia a considerar los informes médicos como pruebas fehacientes de la inculpación de un procesado.

La comprobación médico-legal de la violación en el periodo contemplado, por otro lado, se desarrolló en torno al cuerpo femenino, equiparado - por la idiosincrasia de este delito - tanto al cuerpo del delito como a la escena del crimen. Pese a considerar que los vestigios y las pruebas indagatorias podían encontrarse también en otros cuerpos o elementos materiales, la atención de los expertos, tanto en el plano formal como en la comprobación pericial desarrollada en los tribunales, recayó siempre sobre las víctimas.

La supuesta eliminación formal de la desigualdad que subyacía en el tratamiento colonial del delito de forzamiento, con la elaboración del delito de violación en la codificación penal, dentro de la lógica de los principios liberales de igualdad ante la ley, estuvo acompañada por una desigualdad real. En la práctica, además de la distinción de género establecida, pues el delito

86. Violación de Virginia Rosalva Iriarte, 1898. Archivo Nacional Histórico de Chile, Fondo Judicial Valparaíso, Sección Criminal, caja 71, doc. 9, ff. 43r-43v.

87. Violación de Virginia Rosalva Iriarte, 1898. Archivo Nacional Histórico de Chile, Fondo Judicial Valparaíso, Sección Criminal, caja 71, doc. 9, ff. 77r y 78r. 
de violación operó como un ilícito exclusivamente femenino, los mecanismos procesales que acompañaron su comprobación siguieron excluyendo como víctimas potenciales a aquellas mujeres cuyo himen se encontrara perforado antes de la agresión sufrida, además de centrar los esfuerzos médicos en la verificación del estado de esta membrana y no ya de marcas de violencia. Ante esta situación, las diversas sistematizaciones médico-legales que hemos analizado orientaron la labor pericial hacia la protección de las posibles víctimas no ya de agresiones sexuales sino de posibles acusaciones falsas, manteniendo una desconfianza generalizada ante los relatos femeninos, acorde a las dinámicas imperantes en el contexto occidental ${ }^{88}$. Pese a encontrar algunas excepciones en la práctica forense, la identificación de marcas de violencia, estuvo, tanto en las monografías, como en la mayor parte de los exámenes médicos analizados, limitada a grados considerados excesivos, al valorar que una sexualidad fisiológica implicaba cierta violencia y dudar que la voluntad de una mujer adulta pudiera verse doblegada por la fuerza de un solo varón ${ }^{89}$.

La medicalización de la comprobación delictiva en los procesos por violación de mujeres solteras, por otro lado, coadyuvó a re-significar un concepto de honradez femenina asociado a la castidad y al recato como virtudes, materializándolo en la conservación física y comprobable de su membrana himen. A pesar de las advertencias científicas sobre sus posibles rupturas indirectas, así como de la posibilidad de que ciertas membranas presentaran una elasticidad capaz de resistir una agresión sexual que implicara penetración vaginal, tanto en las obras médico-legales de referencia, como en la práctica judicial, esta impronta material adquirió una creciente centralidad en la determinación del cuerpo del delito, contradiciendo, en la práctica, el pretendido reconocimiento penal de la igualdad formal de las víctimas de violación ante la ley, independientemente de su actividad sexual. De esta manera, dentro de los nuevos parámetros científicos ordenadores, se consolidó la dificultad de probar empíricamente el delito, al presumir «el cuerpo del delito - la mujer en tanto cuerpo femenino-», presuntamente culpable $^{90}$. Más allá de los daños físicos, por otro lado, si bien, como recoge Ruberg, el trauma psiquiátrico ya existía en época pre-psiquiátrica, pese a no conceptualizarse como tal, consideramos que los daños a la persona

88. Quinlan, n. 14, p. 16 y Vigarello, n. 19, p. 225.

89. Vigarello, n. 19, p. 147; Robertson, n. 20, p. 350.

90. Araya, n. 26, p. 82. 
contemplados por Vera o Ramírez, así como al estado nervioso, anímico y general de la salud de las víctimas, contemplados por Puga Borne, estuvieron estrechamente limitados a este mismo concepto de honor femenino.

En relación con la práctica procesal, considerando que el valor probatorio de los exámenes estuvo en entredicho, interpretamos que la acción judicial de ordenar el examen genital de las supuestas víctimas de violación implicaba un acto performativo ${ }^{91}$, ya que además que constatar una realidad -la interpretación de los exámenes como métodos probatorios de la comisión delictiva - creaba y fomentaba un complejo conjunto de relaciones de poder, de significación del cuerpo femenino como espacio y receptáculo de vestigios probatorios, leídos como improntas de una actividad masculina, al tiempo que, paradójicamente, deslegitimaba esta práctica pericial, haciendo uso de su arbitrio para basar los argumentos de sus sentencias en otras circunstancias independientes del criterio médico.

En síntesis, podemos concluir que la inclusión del delito de violación - figura penal de mayor gravedad dentro del conjunto de las agresiones sexuales - como un delito contra el orden de las familias y contra la moralidad pública, la exclusión de los hombres cómo víctimas potenciales, así como la consolidación — gracias a la actuación judicial y médico-legal— de la virginidad de la víctima y de la penetración vaginal como variables determinantes para la constitución criminal, por tanto, promovieron una jerarquía y una significación en la valoración delictiva que sirvieron para consolidar un concepto de violencia sexual actualmente en proceso de de-construcción. 